\title{
The Importance of Light Diagnosis in Joint Injuries of the Walls of the Upper Jaw Cavity
}

\author{
Boymuradov S.A., Karimberdiev B.I., Bakieva S.KH.
}

\begin{abstract}
The article discusses the possibilities of computed tomography and magnetic resonance imaging when examining patients in an ENT clinic. The authors' materials cover complex observations of diseases of the nose and paranasal sinuses. The patients were operated on, which made it possible to compare the data of radiation studies with operational findings and cytological material. CT scan in coronal projection allows to clarify the diagnosis, determine the possible causes of recurrent sinusitis and identify the individual structural features of the nasal cavity and PNS that contribute to the development of intraoperative complications. When analyzing CT data, special attention should be paid to identifying and correctly interpreting the intranasal anatomy. It is necessary to indicate in detail the location of the cyst of the maxillary sinus, which allows the surgeon to correctly choose the optimal surgical access.
\end{abstract}

Keywords: PNS that contribute to the development of intraoperative complications.

\section{INTRODUCTION.}

In the middle part of the upper jaw bone retains an airretaining cavity, so in injuries of the middle part of the face, fracture of the walls of the cavity is observed. Individual injuries to the walls of the upper jaw are rare, so fractures of the walls of the upper jaw are observed in injuries of the middle part of the face. Among these injuries, the cheekorbital complex injury plays an important role. Especially in the case of a fracture of the cheekbone, the anterior part of the cheekbone sinks into the upper jaw cavity $[1,2,4]$. According to the literature, cheek-orbital complex injuries are not always accurately diagnosed (30-95\%). Treatment of injuries of the middle part of the facial bone is mainly focused on restoring the integrity of the cheek and upper jaw, with no emphasis on restoring the integrity of the walls of the upper jaw cavity. This, in turn, prolongs the healing of injuries and leads to complications [2,3,4,5,6,7,9].

\footnotetext{
Manuscript received on 09 September 2021 | Revised Manuscript received on 21 September 2021 | Manuscript Accepted on 15 October 2021 | Manuscript published on 30 October 2021.

* Correspondence Author

Boymuradov Shukhrat Abdujalilovich*, DSc, Professor, Department of Otolaryngology and stomatology, Tashkent Medical Academy, Republic of Uzbekistan, E-mail: shukhrat.boymuradov@tma.uz

Karimberdiev Bakhriddin Ismatullaevich, PhD Researcher, Dean of Multidisciplinary Clinic of Tashkent Medical Academy, Republic of Uzbekistan, E-mail: bakhriddin.karimberdiev@tma.uz

Bakieva Shakhlo Khamidullaevna, DSc, Professor, Department of Otolaryngology and Stomatology, Tashkent Medical Academy, Republic of Uzbekistan, E-mail: shakhlo.bakieva@tma.uz

(c) The Authors. Published by Lattice Science Publication (LSP). This is an open access article under the CC-BY-NC-ND license (http://creativecommons.org/licenses/by-nc-nd/4.0/)
}

In injuries of the middle part of the face, $\mathrm{X}$-rays of the correct projection are usually used, but X-rays of the lateral projection are also used in some cases, as X-rays of the correct projection do not provide accurate information. More accurate information can be obtained in semi-axial, axial, and nasopharyngeal projections. Because the cheekbone tumors are cortical bone, the edge of the eyeball is clearly visible on $\mathrm{X}$-ray diagnosis, the anterior and lateral walls of the upper jaw are also partially visible, and fluid inside the upper jaw cavity can also be assessed when radiographed in a semiaxial projection. However, $\mathrm{X}$-rays do not always provide complete information because the shadow of the other bones of the face is overshadowed, and the X-ray image is overshadowed by the soft tissue tumor. Therefore, in many recent scientific studies, computed tomography (CT), multispiral computed tomography (MSCT) methods emphasize the superiority of conventional radiography and recommend its use. Some authors report that the computed tomography method is up to $92 \%$ accurate $[3,4.6,7,8,10,11,12]$. CT scan allows us to assess the condition of the bones, the condition of the upper jaw, the nature of the fluid inside the cavity, the condition of the mucous membrane. The popularity of digital radiography (DRG) in recent years has led us to view it as a competitive screening method compared to CT, with studies showing a superiority of CT scans in up to 3\% of cases compared to digital X-rays and CT. But the effectiveness of the inspection method by assessing the condition of the injury of the walls of the upper jaw cavity, and the condition of the bones before and after surgery, that is, the repositioning of bone fragments, seems to be effective. In view of the above considerations, we aimed to evaluate the effectiveness of DRG and CT by comparing digital radiography examination.

\section{MATERIALS AND INSPECTION METHODS}

The results of a study of 67 patients with a joint injury of the middle part of the face were examined for examination. Patients ranged in age from 18 to 62,48 of whom were men and 19 were women. All patients were treated in the otorhinolaryngology and maxillofacial surgery departments of the multidisciplinary clinic of the Tashkent Medical Academy. All patients were admitted to the emergency department after the injury, and were admitted to the ward after clinical laboratory examinations. Patients underwent an DRG as directed and were diagnosed and recommended surgical treatment.

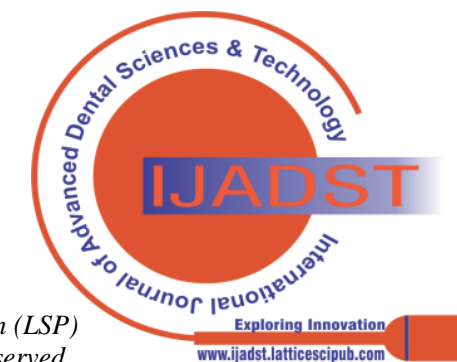




\section{The Importance of Light Diagnosis in Joint Injuries of the Walls of the Upper Jaw Cavity}

An additional CT scan is scheduled to determine the status of the fracture fragments to make a diagnosis on the DRG. All patients underwent DRG or CT as a postoperative follow-up. Of the patients, 62 (92.5\%) received surgical treatment, the remaining $5(7.4 \%)$ received conservative treatment, in which no surgical treatment was performed because the fracture fragments did not move. All patients underwent $n=67$ (100\%) DRGs, and 62 (92.5\%) patients underwent surgical treatment for fractured fractures, of which in $10(15 \%)$ patients, the condition of the fracture fragments was not fully assessed and they were not ordered for re-CT and MSCT examination, in 52 (77.6\%) patients, CT was performed on $n=27$ (40.1\%) patients and MSCT was performed on $n=25$ (37.5\%) patients to fully assess the condition of the fracture fragments and to develop an operation plan (Table 1).

\section{THE RESULTS OF THE INSPECTION AND THEIR DISCUSSION}

When patients underwent DRG or CT, the integrity of the walls of the upper jaw cavity, the condition of the fracture fragments, the volume of fluid in it, or its pneumatization were studied. In fractures of the cheekbone and eyeball, the nature of the fracture was assessed and a plan of operative treatment was developed. Indications such as upper jaw cavity after surgery, restoration of the integrity of the walls, the presence or absence of hematosynus, restoration of cavity pneumatization were studied in all operatively treated patients. Fractures of the anterior wall of the frontal bone, violation of the integrity of the lower edge of the eyeball, fractures of the cheekbone are well visible on DRG (Figure 1.2), but the position of the anterior, medial, lateral, upper and lower walls of the upper jaw is not good on DRG, these changes looks good (Figure 3.4). In DRG, bone surface can be assessed in one plane, while in MSCT, bone surface can be assessed in three planes, namely, saggittal, vertical, and horizontal planes (Figure 5). According to the analysis of the results obtained in Table 1 , only $59.1 \%$ of patients who underwent DRG had fractures identified, while the remaining $41.9 \%$ had no opportunity to assess the status of fractures. CT scans show that it is possible to assess the condition of fractures in $100 \%$ of patients (Table 1). In addition, the presence of hematosinus was clearly visible on the DRG, only the upper jaw cavity was shaded, pneumatization was also visible, but it was not possible to fully determine the nature of the shadow within the cavity. The cortical bones of the upper jaw are visible in the DRG, but the porous portion of the bones, the walls of the cavities, are not fully visible. In MSCT, the nature of the fluid was assessed by Hausfelt and it is measured in Hausfelt units (HU). According to him, he defined the density of water as 0 , its increase as + and its decrease as -. In our examinations, it was found that in the post-injury period, when examined in the range of 1-3 days, it was in the range of $\mathrm{HU}+20, \mathrm{HU}+30$. This indicator indicated the presence of blood in the cavity. Light diagnosis of joint injuries of the walls of the upper jaw cavity

Table 1

\begin{tabular}{|l|c|c|c|c|c|}
\hline $\begin{array}{c}\text { Types of light } \\
\text { diagnosis }\end{array}$ & $\begin{array}{c}\text { Number of } \\
\text { patients }\end{array}$ & $\begin{array}{c}\text { The displacement } \\
\text { of the broken } \\
\text { piece was detected }\end{array}$ & $\begin{array}{c}\text { The presence of } \\
\text { hemato sinus }\end{array}$ & $\begin{array}{c}\text { Pneumatization is } \\
\text { partially preserved }\end{array}$ & $\begin{array}{c}\text { Postoperative re-light } \\
\text { diagnosis }\end{array}$ \\
\hline DRG & $67(100 \%)$ & $62(92,5 \%)$ & $62(92,5 \%)$ & $62(92,5 \%)$ & $10(15 \%)$ \\
\hline CT & $27(40,1 \%)$ & $27(40,1 \%)$ & $27(40,1 \%)$ & $27(40,1 \%)$ & $27(40,1 \%)$ \\
\hline MSCT & $25(37,5 \%)$ & $25(37,5 \%)$ & $25(37,5 \%)$ & $25(37,5 \%)$ & $25(37,5 \%)$ \\
\hline
\end{tabular}

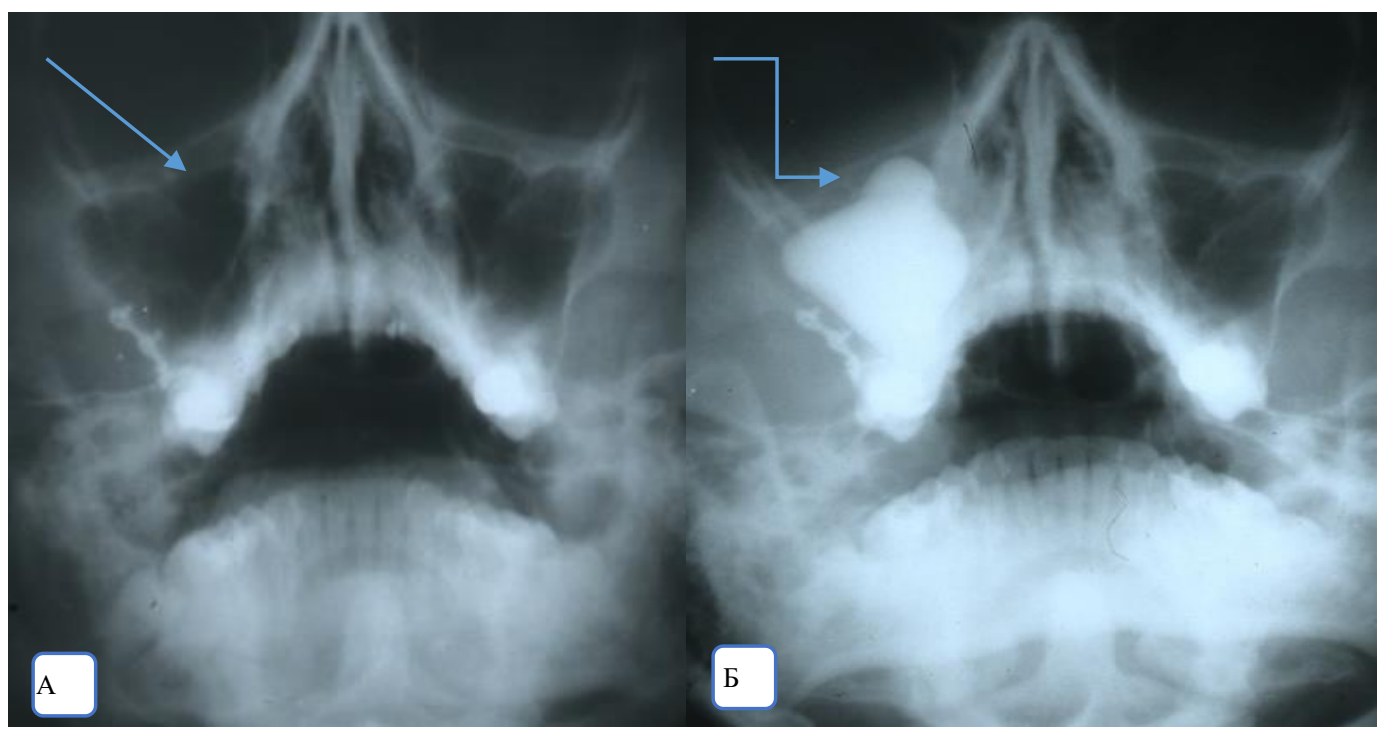

Figure 1.2. Fracture of the upper wall of the right upper jaw cavity in axial projection in DRG (A), preoperative and postoperative endothelial position (B).

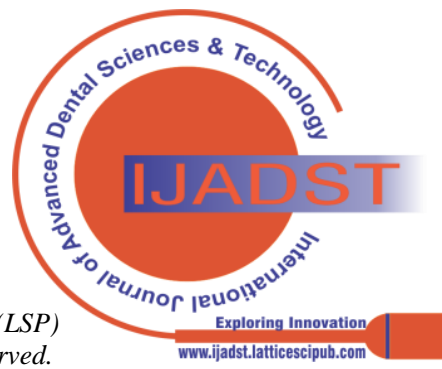




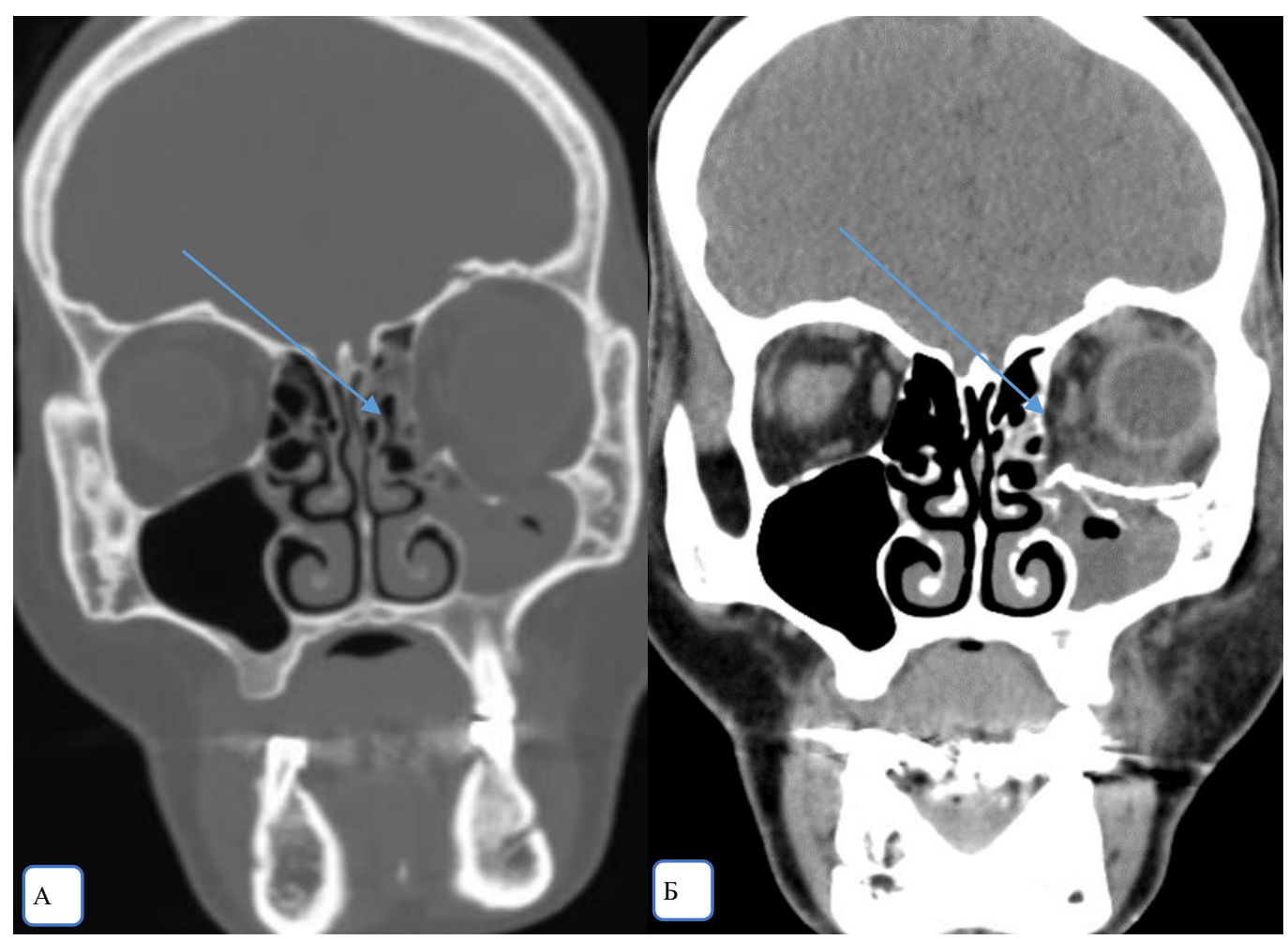

Figure 3.4. In CT, the left side of the sagittal incision is fractured and displaced by the upper wall of the upper jaw cavity, the preoperative position of the hematosinus (A) and the postoperative position of the upper wall of the upper jaw cavity restored with titanium plate $(B)$.

In the 6-10 days after injury, this figure was found to be $\mathrm{HU}+40$, or $\mathrm{HU}+50$, indicating that the blood transfused into the cavity was condensed. Another difference from other examinations in MSCT examination can be seen the 3D effect of bone fractures, which allows to assess the condition of pre-operative and postoperative fractures, the effectiveness of the operation (Figure 6).

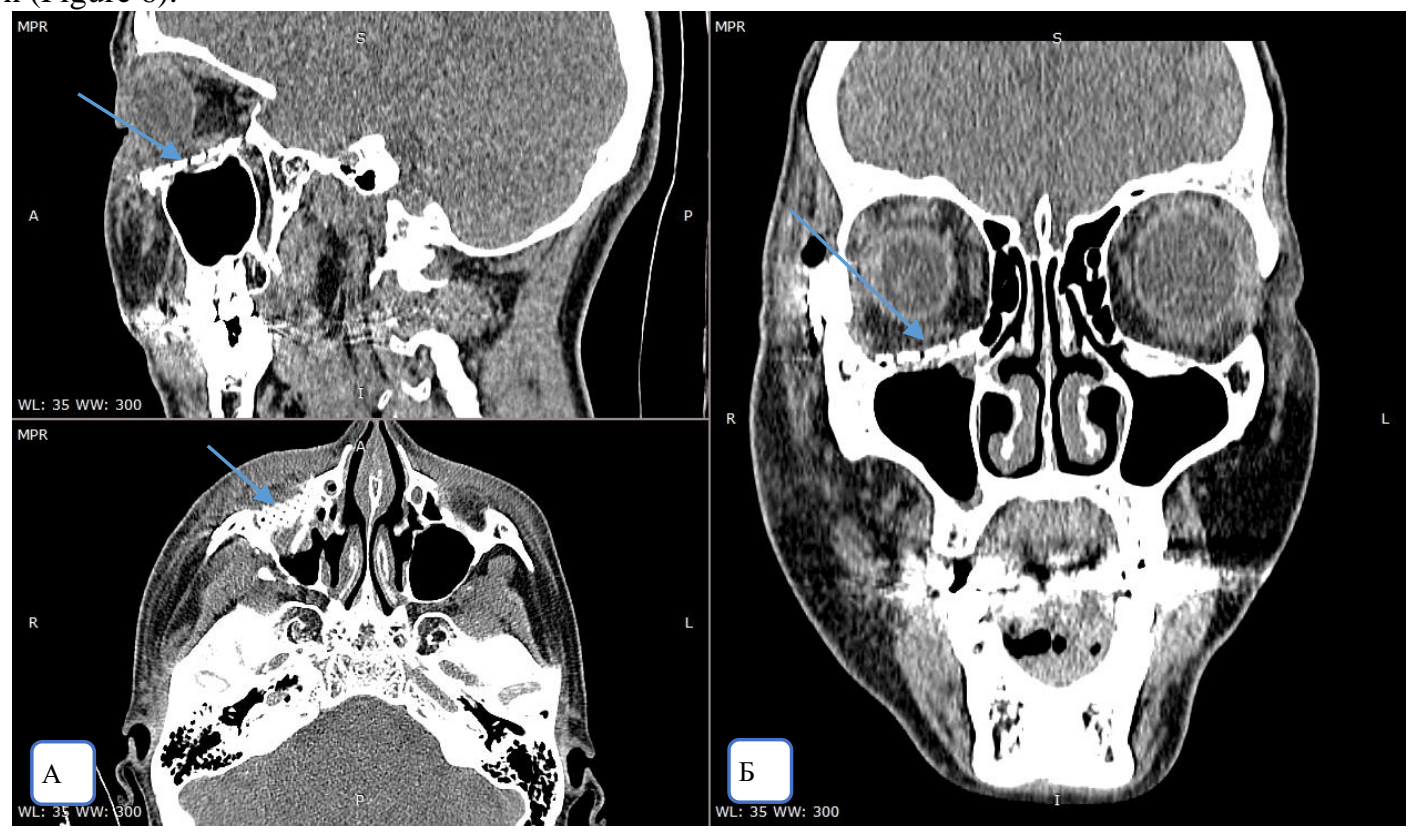

Figure 5. Reconstructed postoperative titanium plate of the upper wall of the right maxillary cavity in the saggital, vertical (A), and horizontal section (B) in the MSCT.

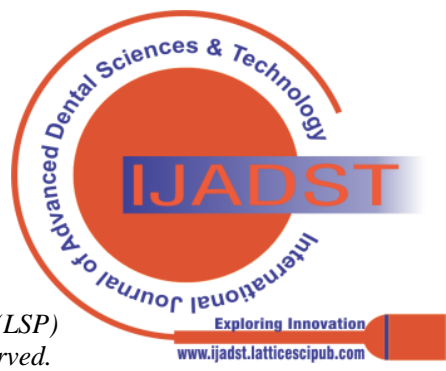




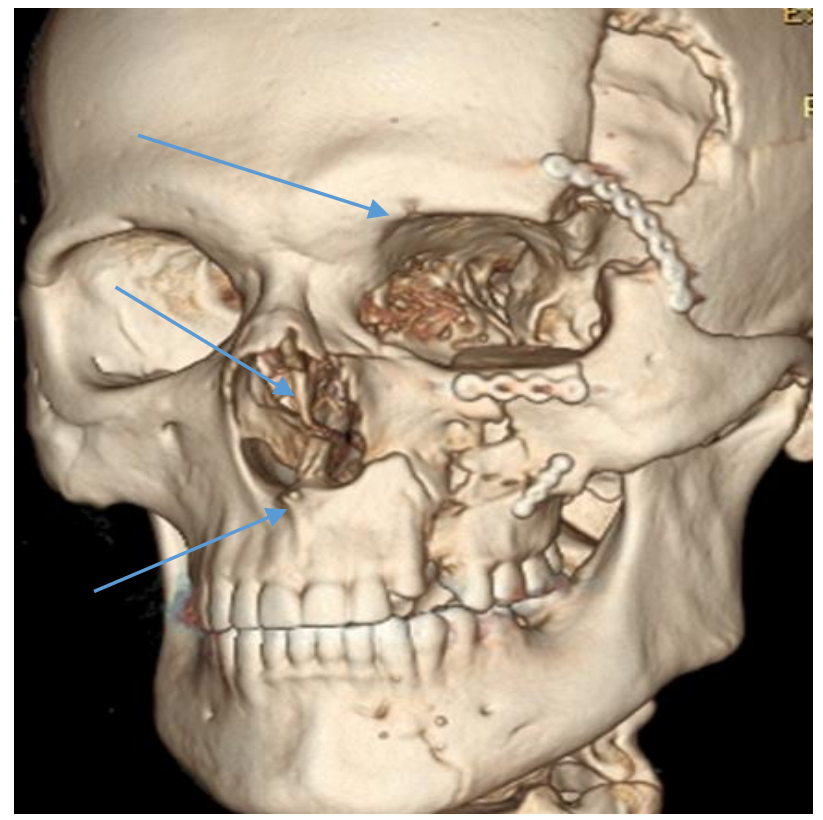

Figure 6. Fracture of the left upper jaw bone in axial projection in MSCT, 3D postoperative image restored using a titanium plate.

According to the Hausfeld unit, if this density indicator is $\mathrm{HU}+60$, it means that there is liquid pus, when the pus thickens, this indicator is in the range of $\mathrm{HU}+80, \mathrm{HU}+100$. Density in the range of $\mathrm{HU}+100, \mathrm{HU}+150$ indicates that it is specific to soft tissue, and values in the range of $\mathrm{HU}+200, \mathrm{HU}+400$ indicate that it is specific to bone tissue density.

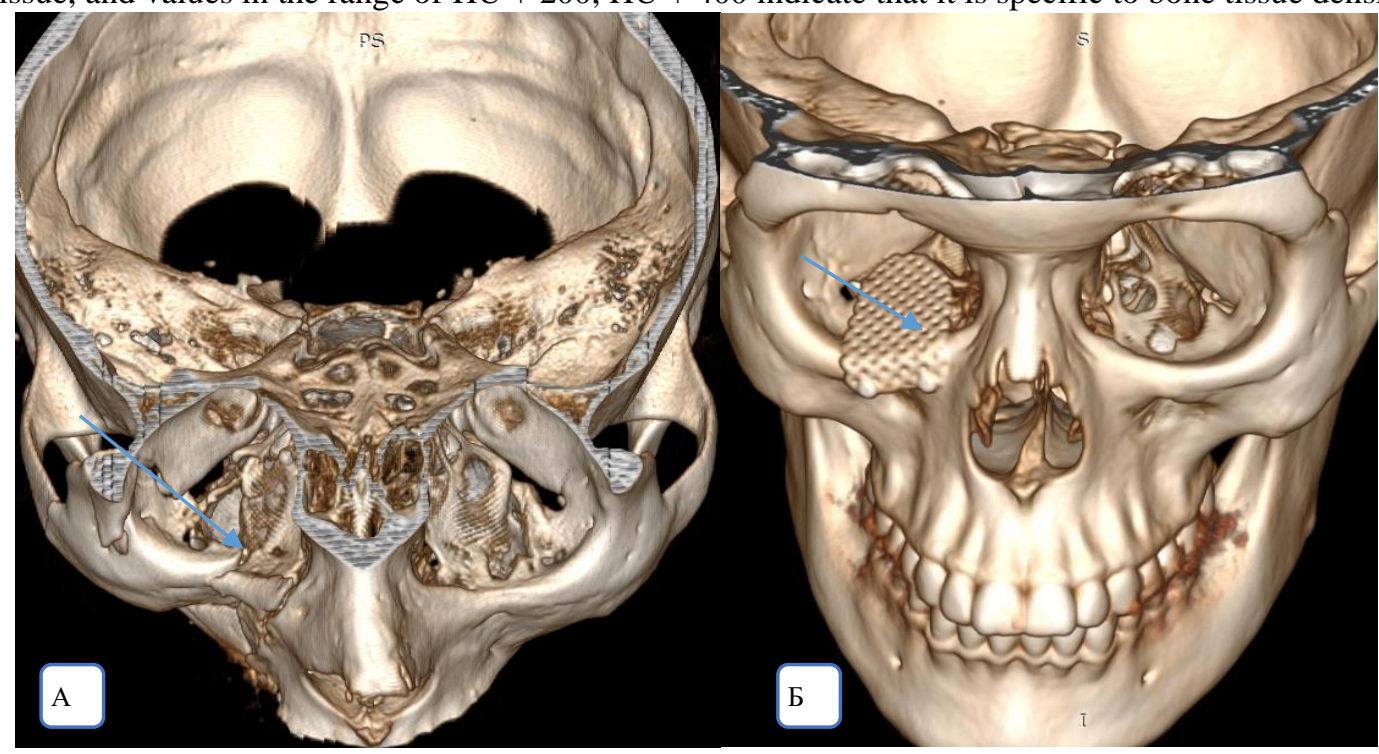

Figure 7. Fracture of the left upper jaw bone in axial projection in MSCT (A), postoperative 3D image reconstructed using a titanium plate $(B)$.

When patients were admitted to the ward after injury, they were given emergency care, so an DRG was performed. In most cases, a follow-up MSCT was performed in the days following the injury to determine the condition of the fractures and to plan the operation. $92.5 \%$ of the examined patients were treated surgically, of which $40.1 \%$ underwent CT and $37.5 \%$ underwent MSCT. Outcomes of surgical treatment of patients with joint injury of the upper jaw cavity walls

Table 2

\begin{tabular}{|l|l|c|c|}
\hline$№$ & Types of operations & \multicolumn{2}{|c|}{ Number of patients } \\
\hline 1 & Restoration of the upper jaw upper cavity using a titanium plate & $\mathrm{n}=18$ & $29,3 \%$ \\
\hline 2 & Restoration of fractures of the upper jaw using miniplates & $\mathrm{n}=14$, & $22,3 \%$ \\
\hline 3 & Reposition of the cheek-orbital complex & $\mathrm{n}=30$ & $\mathrm{n}=62$ \\
\hline & TOTAL & $100 \%$ \\
\hline
\end{tabular}

$29.3 \%$ of the monitored patients underwent surgery to restore the upper jaw upper cavity using titanium plate, $22.3 \%$ of patients had upper jaw fractures repaired using miniplastins, and $48.4 \%$ of patients underwent cheek-orbital complex repositioning (Table 2).

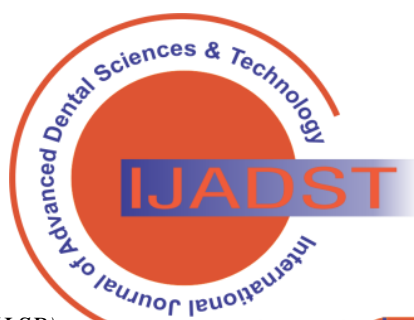


When the patients underwent postoperative MSCT, the postoperative condition of the fracture fragments was satisfactory in all patients, it was found that the under-eye edge was completely restored, and there was no need to rediagnose them. In all MSCT patients, intra-maxillary fluid and blood were found to be absorbed. In injuries of the upper wall of the upper jaw cavity, the condition of the implant placed along with the fracture fragments in the postoperative period was assessed, in which it was found that the implants completely restored the defect of the subconjunctival wall, the implants did not damage the surrounding tissue.

\section{CONCLUSION}

Thus, it can be concluded that the anterior and lateral as well as the upper walls of the upper jaw are most injured among the walls of the upper jaw. When using DRG to assess upper jaw wall injuries, it is $80 \%$ effective, with the remaining $20 \%$ requiring re-examination. In DRG, the condition of the cortical edges of the upper jaw appears good, but it is not possible to assess the condition of the anterior, lateral, medial, upper walls of the upper jaw cavity, so it is not fully effective. The study of the condition of the fracture fragments, the hematosynus within the cavity, as well as the study of the integrity of the upper wall, will require the use of MSCT to plan its restoration of integrity. MSCT will also be needed to assess the condition of the fractures in the postoperative follow-up examination. Based on the results of the MSCT examination, it is possible to assess the condition of the fractures $100 \%$.

\section{REFERENCES}

1. Babina, A.I. Anatomical aspects of plastic surgery of the anterior wall of the maxillary sinus with connective tissue allografts: dissertation of the candidate of medical sciences - Ufa, 2018.-p.200.

2. Bojokov, A.R. Plastics of bone defects in the walls of the paranasal sinuses with demineralized bone grafts: thesis of doctor of medical sciences - Rostov n / a, 2012. - p.56.

3. Golovko K.P. et al. Therapeutic tactics for damage to the paranasal sinuses in patients with severe concomitant trauma // Russian otorhinolaryngology. - 2010. - No. 3. — pp. 52-63.

4. Zubareva A.A. et al. Possibilities of digital volumetric tomography in otorhinolaryngology, maxillofacial surgery and surgical dentistry // Medical alphabet. - 2012. - No. 7. - pp. 18-24.

5. Kryukov A.I. et al. Anatomical and histological features of the state of the structures of the ostiomeatal complex in patients with cystic lesions of the maxillary sinus // Russian otorhinolaryngology. - 2016. - No. 2 (81). - pp. 60-65.

6. Mareev O.V. et al. Computer craniometrics using modern technologies in medical // Morphological statements. - 2015. - No. 1. - pp. 49-54.

7. Piskunov S.Z. et al. Anatomical and morphological features of the nose and paranasal sinuses of a rabbit // Russian rhinology. - 2015. - T. 23 , No. 3. - pp. 36-41. [CrossRef]

8. Khatskevich G.A. et al. To the question of the algorithm for radiation diagnosis of fractures of the midface zone, accompanied by damage to the maxillary sinus // Radiation diagnostics and therapy. -2014. - №4.pp.57-62.

9. Mehta N. The imaging of maxillofacial trauma and its pertinence to surgical intervention // Radiologic Clinics of North Amer. - 2012. № 1. - pp. 43-57. [CrossRef]

10. Naveen Shankar A. The pattern of the maxillofacial fractures: a multicentre retrospective study // J. of Cranio-Maxillo-Facial Surgery. 2012. — № 8. — pp. 675-679. [CrossRef]

11. Salentijn E. G. A ten-year analysis of midfacial fractures // J. of Cranio- Maxillofacial Surgery — 2013. — № 7. — pp. 630-636. [CrossRef]

12. Sohns J. M. Current perspective of multidetector computed tomography (MDCT) in patients after midface and craniofacial trauma // Clinical Imaging.- - 2013.— № 4.— pp. 728-733[CrossRef]

\section{AUTHOR PROFILE}

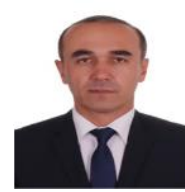

Boymuradov Shukhrat Abdujalilovich, DSc, Professor, Department of Otolaryngology and stomatology, Tashkent Medical Academy, Republic of Uzbekistan, e-mail: shukhrat.boymuradov@tma.uz

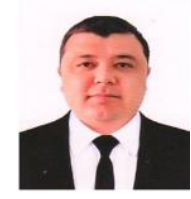

Karimberdiev Bakhriddin Ismatullaevich, $\mathrm{PhD}$ researcher, dean of multidisciplinary clinic of Tashkent Medical Academy, Republic of Uzbekistan, e-mail: bakhriddin.karimberdiev@tma.uz,

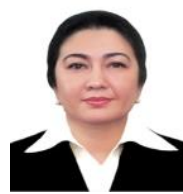

Bakieva Shakhlo Khamidullaevna, DSc, Professor, Department of Otolaryngology and stomatology, Tashkent Medical Academy, Republic of Uzbekistan, email: shakhlo.bakieva@tma.uz,

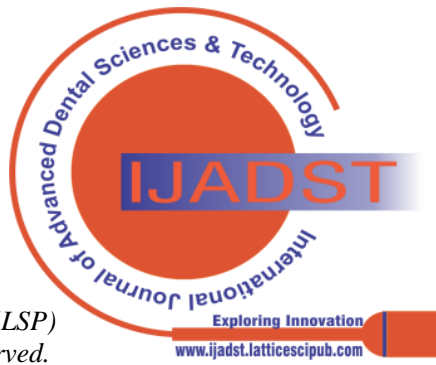

